\title{
Enzymatic processing of protein-based fibers
}

\author{
Jiajia $\mathrm{Fu}^{1}$ • Jing Su ${ }^{1}$ - Ping Wang ${ }^{1}$ - Yuanyuan $\mathrm{Yu}^{1}$ • Qiang Wang ${ }^{1}$. \\ Artur Cavaco-Paulo ${ }^{1,2}$
}

Received: 16 April 2015 /Revised: 25 August 2015 / Accepted: 28 August 2015 /Published online: 1 October 2015

(C) Springer-Verlag Berlin Heidelberg 2015

\begin{abstract}
Wool and silk are major protein fiber materials used by the textile industry. Fiber protein structure-function relationships are briefly described here, and the major enzymatic processing routes for textiles and other novel applications are deeply reviewed. Fiber biomodification is described here with various classes of enzymes such as protease, transglutaminase, tyrosinase, and laccase. It is expected that the reader will get a perspective on the research done as a basis for new applications in other areas such as cosmetics and pharma.
\end{abstract}

Keywords Protein fiber - Biomodification · Protease · Transglutaminase $\cdot$ Tyrosinase

\section{Introduction}

Wool and silk are protein-based materials from animal origin. Those fibers possess moderate strength, resiliency, elasticity,

Jiajia Fu and Jing Su contributed equally to this work.

Electronic supplementary material The online version of this article (doi:10.1007/s00253-015-6970-x) contains supplementary material, which is available to authorized users.

Qiang Wang

qiang_wang@163.com

$\checkmark$ Artur Cavaco-Paulo

artur@deb.uminho.pt

1 Key Laboratory of Science and Technology of Eco-Textile, Ministry of Education, Jiangnan University, Wuxi, Jiangsu 214122, China

2 Centre of Biological Engineering (CEB), University of Minho, 4710-057 Braga, Portugal acid resistance, and moisture absorbency. Similar to any other proteins, the proteins from wool and silk are made of polypeptides. In wool and silk, polypeptide chains assemble to form a fibrous structure. Fibrous proteins are mainly characterized by their protein primary (amino acid sequence and composition) and secondary structures (hydrogen bonding interaction between the polypeptides). The secondary structure (Fig. 1a) is an alpha helix for keratin-based fibers like wool or hair. For silk and spider silk materials, the polypeptide chains show beta-sheet in secondary structure (Fig. 1b).

Fiber properties such as elasticity and chemical resistance are derived from the secondary structure of the fiber. Alpha helix will assemble in a parallel fashion, and the helices can be stretched inducing higher elasticity in wool and hair fibrous materials. In the silk-based materials, beta structures also assemble in a parallel format, providing a more compact structure and a higher resistance to chemical attack. The high elasticity and loose structure of wool leads to higher water retention levels than silk, which results in a fibrous material with high capacity of wrinkle recovery. Moreover, due to their secondary structure, wool fibers possess natural crimps which lead to textile materials with excellent thermal insulation properties (Braaten 2005). Because of these characteristics, wool fiber is widely used as a textile material. Silk fiber materials have more compact protein structures of beta type. These materials produced by Bombyx mori have softer handle and luster. Silk fibroins form predominantly crystalline-sheet structures mainly composed of recurrent amino acid sequences of alanine, glycine, and serine, which determine the structural and mechanical characteristics of silk fibers (Hu et al. 2007; Sionkowska and Planecka 2011). Silk materials do not have any traceable amounts of cysteine in their structure, while wool and hair materials have a higher level of cystine crosslinking. Typical amino acid compositions of wool and silk are given in Table $\mathrm{S} 1$. 
Fig. 1 The secondary structure of wool and silk: a Alpha helix in secondary structure of wool (right handed $\alpha$-helix) and $\mathbf{b}$ beta-sheet in secondary structure of silk (parallel $\beta$-pleated sheet) (made with ChemDraw adapted from Kumaran 2010) (a)

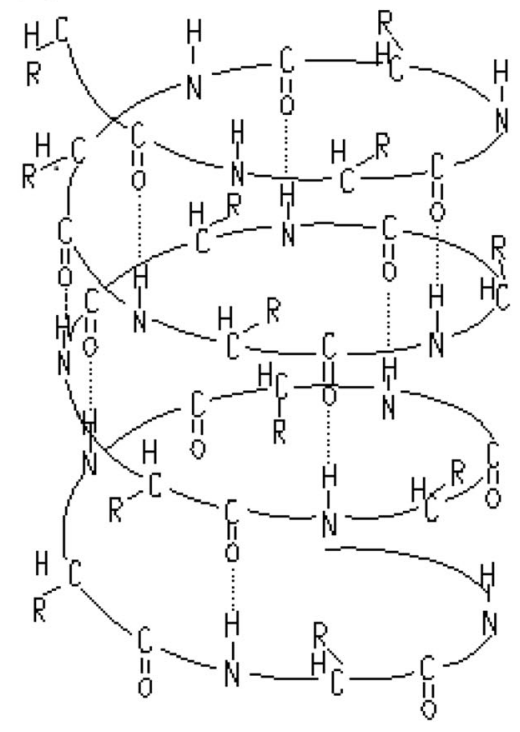

(b)

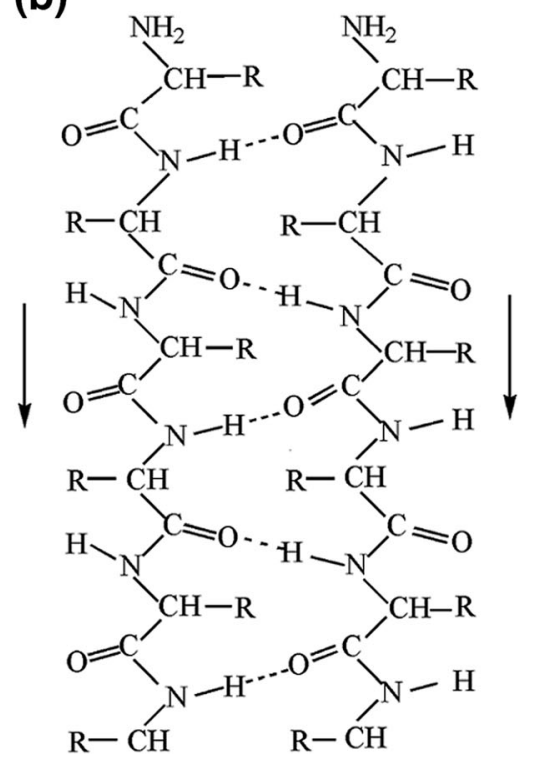

The difference in the structure between wool and silk is shown in Fig. 2. Wool fiber presents scales on their surface (as shown in Fig. 2a), whereas silk fiber exhibits a smooth surface (as shown in Fig. 2c). The scales on the wool surface cause severe felting during washing and thus limit the use of untreated wool materials as machine-washable textiles (Simpson 2002). Silk fiber has some inherent disadvantages such as it is easily damaged during alkaline scouring, it wrinkles, and it undergoes photoinduced yellowing (Yang and $\mathrm{Li}$ 1993), which narrows its application in textiles and other biomaterial fields (Arai et al. 2001). Wool and silk show a significant difference in their fine structures. The potentially available enzymes for their structural degradation are also highlighted in Fig. 2b, d.

\section{Processing of wool}

Wool materials have a tendency to felt due to the presence of scales (Fig. 2a). Wool fibers would interslide resulting in thicker fiber assemblies. The scale structure of wool results in less friction when fiber moves in a rootward direction than in a tipward direction. This difference in the surface friction between the two directions is known as the direction friction effect.

Different mechanisms have been put forward to explain how wool felts. A wool fiber is considered to interact with other fibers at two points along its length (Fig. 3). At point $\mathrm{B}$, the interaction is too strong to move in any direction. At point $\mathrm{A}$, the fiber is less strongly held under mechanical action (for example, laundering) and it can move relative to the other fibers. Because of the directional frictional effect, it can move towards its root but not towards its tip (case 1, Fig. 3a), then the single fiber's movement could decrease the distance along the fiber between the points of interaction and make the fiber structure tight. Alternatively, when point B is near the root end of the fiber (case 2, Fig. 3b), movement towards the root end increases the distance along the fiber. Both cases 1 and 2 contribute to fabric shrinkage.

The decreasing felting propensity of wool is obtained by smoothening of the scale structure at the surface fiber (Fig. 2a). The scale of wool is composed of hydrophobic lipids, highly crosslinked keratin, and nonkeratinized protein organized in layers from outer to inner part of the wool. The modification of the wool surface aiming at damaging or dislodging the scale has a significant effect on the processing and performance of the wool fibers and their assemblies. Lots of innovative and novel technologies for the surface modification of wool fiber about scale removal have been developed, especially for the improvement of anti-felting finishing. To date, physical, chemical, and enzymatic approaches have been widely studied. Plasma and steam explosion as physical methods could etch or cleave the surface of the cuticle scales and improve wettability, dye ability, and felting resistance. The chemical approaches such as chlorination and oxidation with hydrogen peroxide and potassium permanganate, ozone, and other chemical treatments can increase adsorption properties and reduce shrinkage and felting of wool fabrics. Some chemical modifications of wool, like chlorination with di-chloro-isocyanuric acid (DCCA) treatment, are effective, but chlorine remains on fiber and this is not wanted by the consumers.

Enzymatic treatments to reduce wool tendency to shrink are known for over 60 years (Middlebrook and Phillips 1941). The amount of disulfide bonding and previous process history of wool are of paramount importance on the success of protease as an anti-shrinking agent. It is the view of some authors (Araújo et al. 2009) that anti-felting finishing based on protease is still 


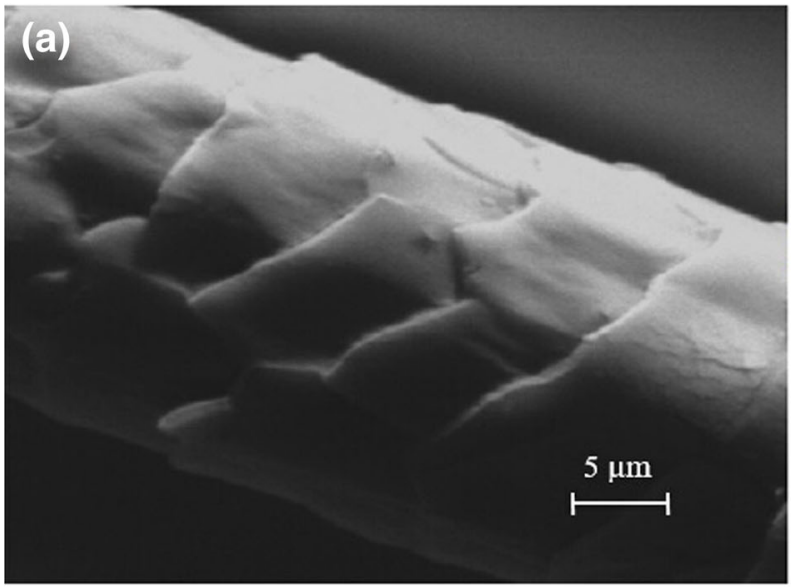

(b)
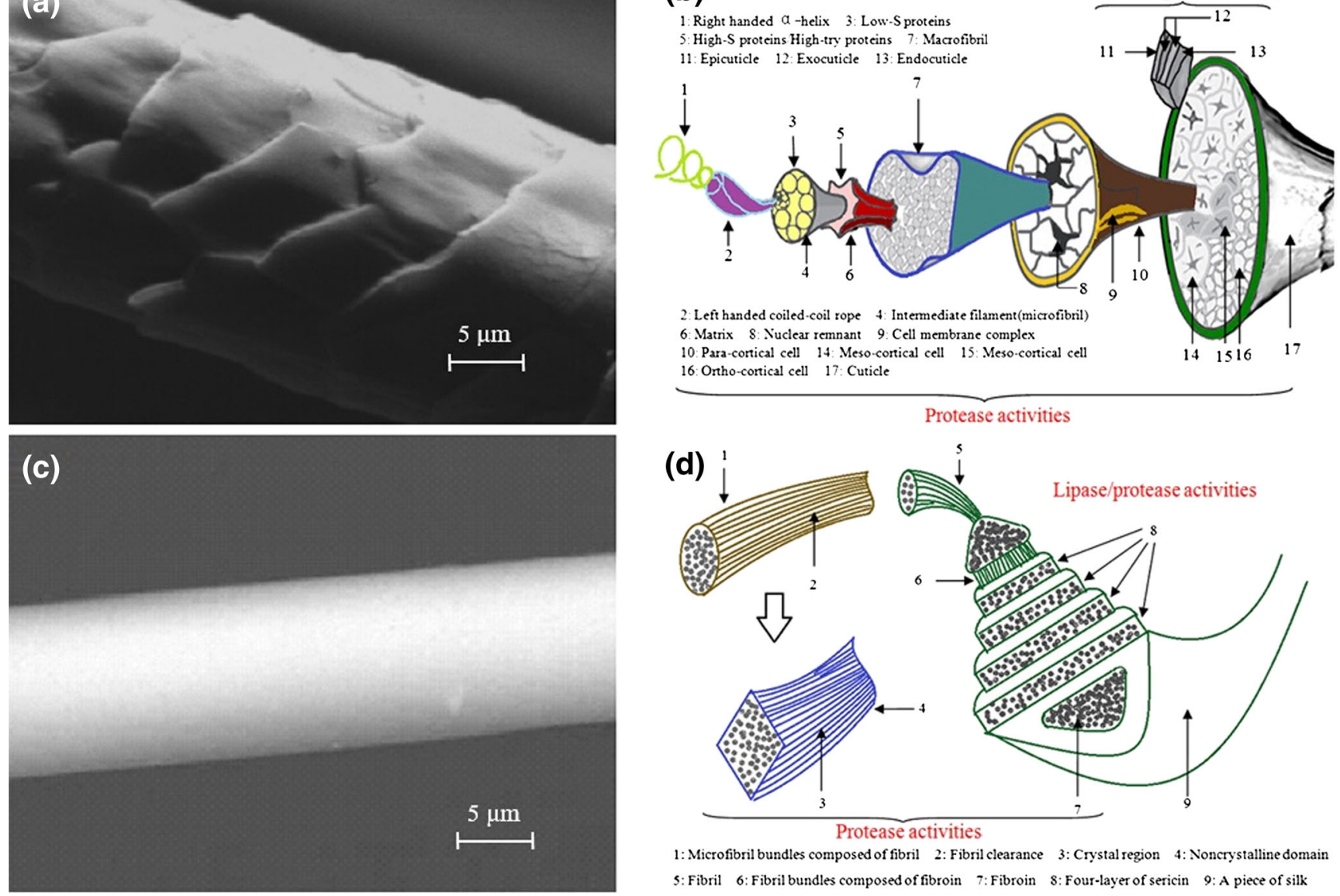

(d)
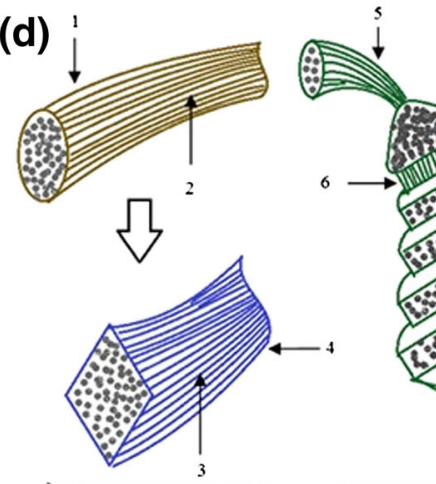

Lipase/protease activities

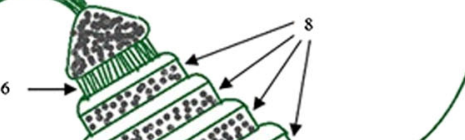

Protease activities

1: Microfibril bundles composed of fibril 2: Fibril clearance 3: Crystal region $\quad$ 4: Noncrystalline domain

5: Fibril 6: Fibril bundles composed of fibroin $\quad 7:$ Fibroin $\quad 8:$ Four-layer of sericin $\quad 9:$ A piece of silk

Fig. 2 Fiber scanning electronic micrographs (SEM) and structural schemes showing possible substrate areas for enzyme: a SEM structure of wool (Zou and Zhang 2007); b structural scheme of wool; c SEM structure of silk (Jin et al. 2013); d structural scheme of silk

the most promising alternative to the chlorination process. Other enzymatic applications for wool are detailed later in this review.
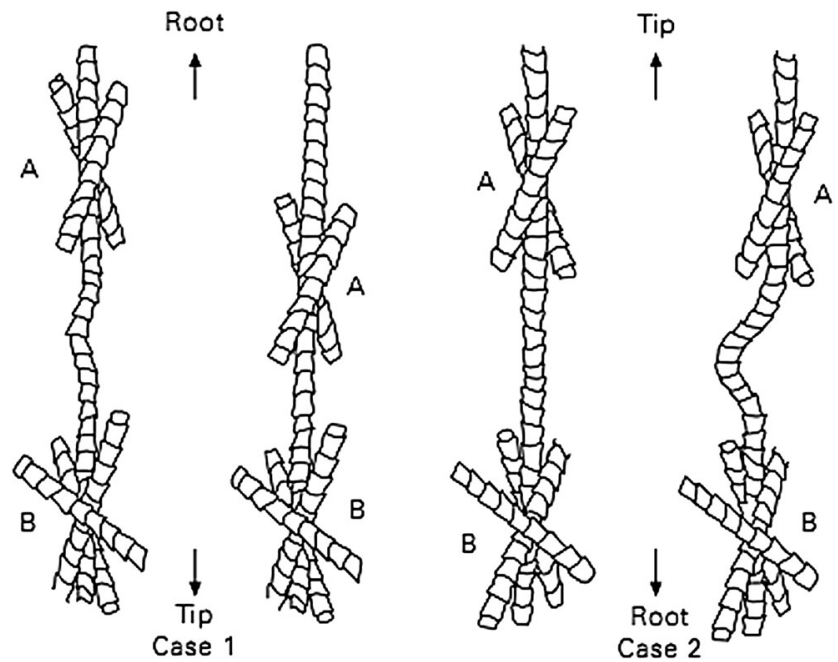

Fig. 3 Schematic diagram of Shorter's mechanism of wool felting: a movement towards tip and b movement towards root (Rippon 1992)

\section{Processing of silk}

Raw silk fiber contains two structural filaments consisting of fibroin and sericin. Other minor components are waxes, pigments, and mineral components (Hakimi et al. 2007; Vepari and Kaplan 2007). Sericin and impurities can be removed during degumming (Fig. 2). Silk fibroins are reported as biomaterials in many fields owing to their biocompatibility with mammal cells (Altman et al. 2003).

A conventional chemical degumming process normally generates plenty of wastewater and causes pollutions mainly due to the presence of detergents. Sericin waste is biodegradable, and it is considered as a valuable resource for many industries including cosmetics, pharmaceutical, and biomedical (Wu et al. 2007). More recently, numerous studies have been carried out aiming at optimizing the treatment methods and improving the performances of the silk products, such as enzymatic degumming, eco-friendly biomodification of silk, and developing acceptable methods of sericin recovery from cocoon cooking and degumming wastewaters. The 
possible uses of enzymes on different parts of silk fibers are systematically shown in Fig. 2 d.

\section{Enzymatic processing of wool}

Wool is a very heterogeneous fiber material, and the gender, feed, age, and climate where the sheep is raised all affect the fiber characteristics such as the fiber diameter and the amounts of lipids present on the surface of the epicuticle. Lipids can prevent the contact of a protease on the surface of the fiber (Bishop et al. 1998), and therefore, the performance of proteases will depend on the characteristics of wool fiber. Proteases are known to hydrolyze keratins and would appear ideal for degrading the cuticle scales on the wool fiber surface leading to shrink proofing of the wool fiber (Erlacher et al. 2006; Wang et al. 2010). It was found by many authors that proteases can diffuse inside the wool fibers causing degradation (Araújo et al. 2009). The ideal enzymatic treatment should restrain enzyme action at cuticle on the wool surface.

One approach has been reported to enhance the surface hydrolysis of wool using a protease modified with natural or synthetic polymers. The modified protease had larger molecular weight and volume. The catalysis of the enlarged protease molecules could be limited to only the fiber surface, thus reducing wool damage. Higher molecular weight proteases were obtained by covalently linking them with PEG (Silva et al. 2005; Schroeder et al. 2006; Jus et al. 2007). Other approaches include attachment to polyacrylic resins and cellulosic derivatives (Cavaco-Paulo and Silva 2002; Silva et al. 2006a; Silva et al. 2006b; Shen et al. 2007; Smith et al. 2008, 2010). Figure $4 \mathrm{a}, \mathrm{b}$ shows the fluorescence microscopy images of fiber cross sections of wool yarns treated with fluorescein isothiocyanate (FITC)-labeled commercial-free subtilisin and linked Eudragit polymer. It is clear that the wool treated with the modified protease possesses good levels of shrink resistance without considerable damage to the fabric because of limited degradation to the fiber cuticle cells of wool during enzymatic treatments. Figure $4 \mathrm{c}$ shows the effect of enzyme treatment with native or modified Esperase (covalently linked to Eudragit S-100) on scoured wool fabrics with increasing amounts of enzyme. More native enzyme added to the bath treatment led to more tensile strength loss of the fabric. However, this fact was not verified for the fabric treated with the immobilized form. In all those reports, wool treated with the enlarged proteases presented good level of shrink resistance with a reduced strength loss. Araújo et al. (2009) successfully constructed novel high molecular weight subtilisin based on the fusion Bacillus subtilis pro-subtilisin E with an elastin-like polymer (ELP). The resulting fusion protein was expressed in Escherichia coli, purified, and used for wool finishing assays. The recombinant subtilisinE-VPAVG220 activity was restricted to the cuticle of wool, thus allowing a
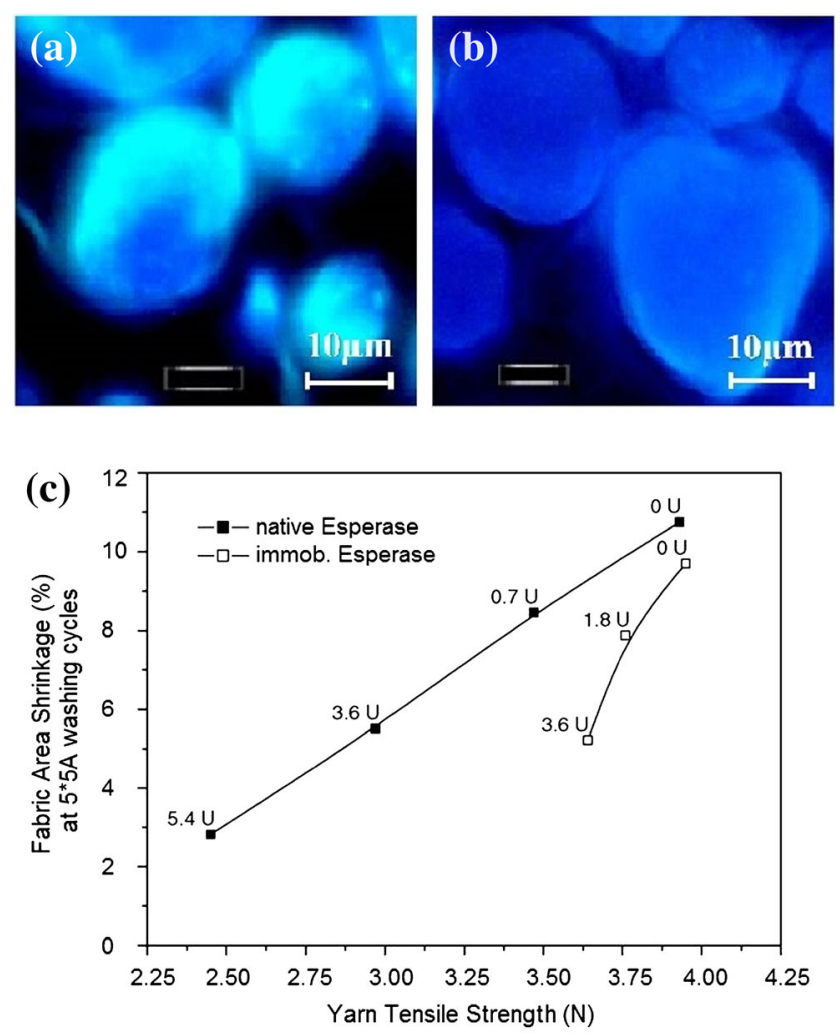

Fig. 4 Effect of enzyme treatment with native or modified Esperase (covalently linked to Eudragit S-100) on scoured wool fabrics: a FITClabeled commercial free subtilisin; b FITC-labeled subtilisin-linked Eudragit polymer; $\mathbf{c}$ relation between shrinkage and strength with increasing amounts of enzyme (measured as total enzyme units in the bath treatment) (Silva et al. 2006b)

significant reduction of pilling, weight loss, and tensile strength loss of wool fibers, while meanwhile imparting wool shrinkage resistance properties. This was the first report of the microbial production for controlled enzymatic hydrolysis of wool surface. The anti-felting mechanism by modified protease is shown in Fig. 5.

Rippon (1992) further reported the relationship between the structure of wool and enzymes (Table S2). Figure 2b shows schematically wool fiber and the possible enzymes that can modify wool. Zhou et al. (2011) used keratinase from Bacillus subtilis and protease to treat wool in one bath. The modified wool reached machine-washable requirement, but the strength loss was high and the high alkali solubility (exceeded $15 \%$ ) also meant serious damages to wool. Keratinase is a poorly defined enzyme activity yet to be clarified by experimental evidence.

Laccase has once been reported to be effective in antifelting of wool (McDevitt and Winkler 2000). Lantto et al. (2004) found that Myceliophthora thermophila laccase/ violuric acid (VA) system could degrade cystine and laccase/ 1-hydroxybenzotriazole (HBT) system could oxidize tyrosine.

The acceptance of a good wool anti-felting treatment is always associated with low strength loss. As describe in 


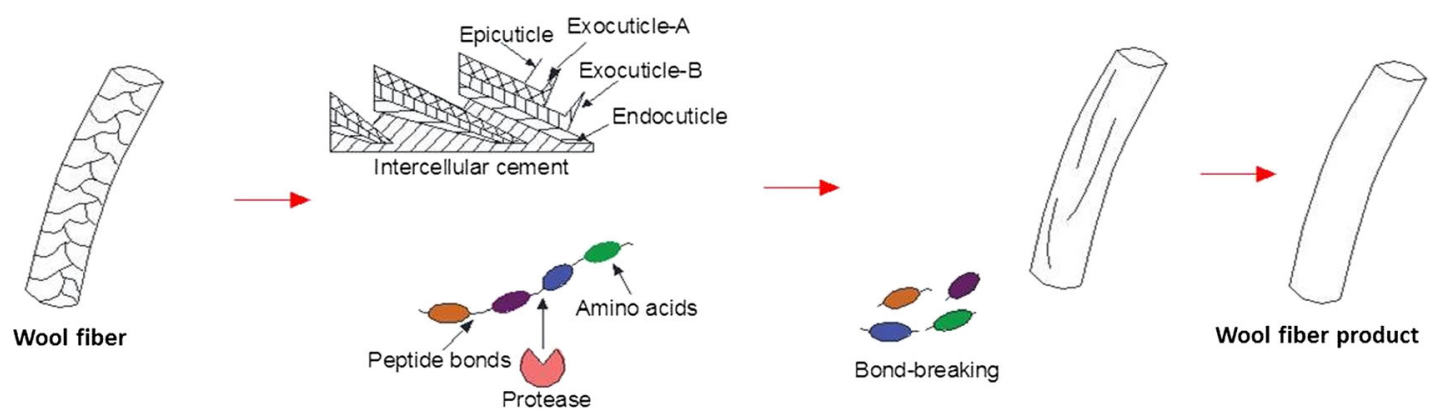

Ideal concept for anti-felting finish with proteases

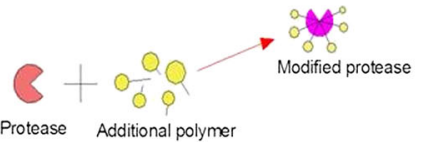

Additional polymer-

1- Linked by chemical bonding with lysine residues of protease to eudragit polymer (Silva, 2006)

2- Fusion protein, by genetic eng of subtilisin with (VPAVG) $_{220}$ (Araújo et al. 2009)

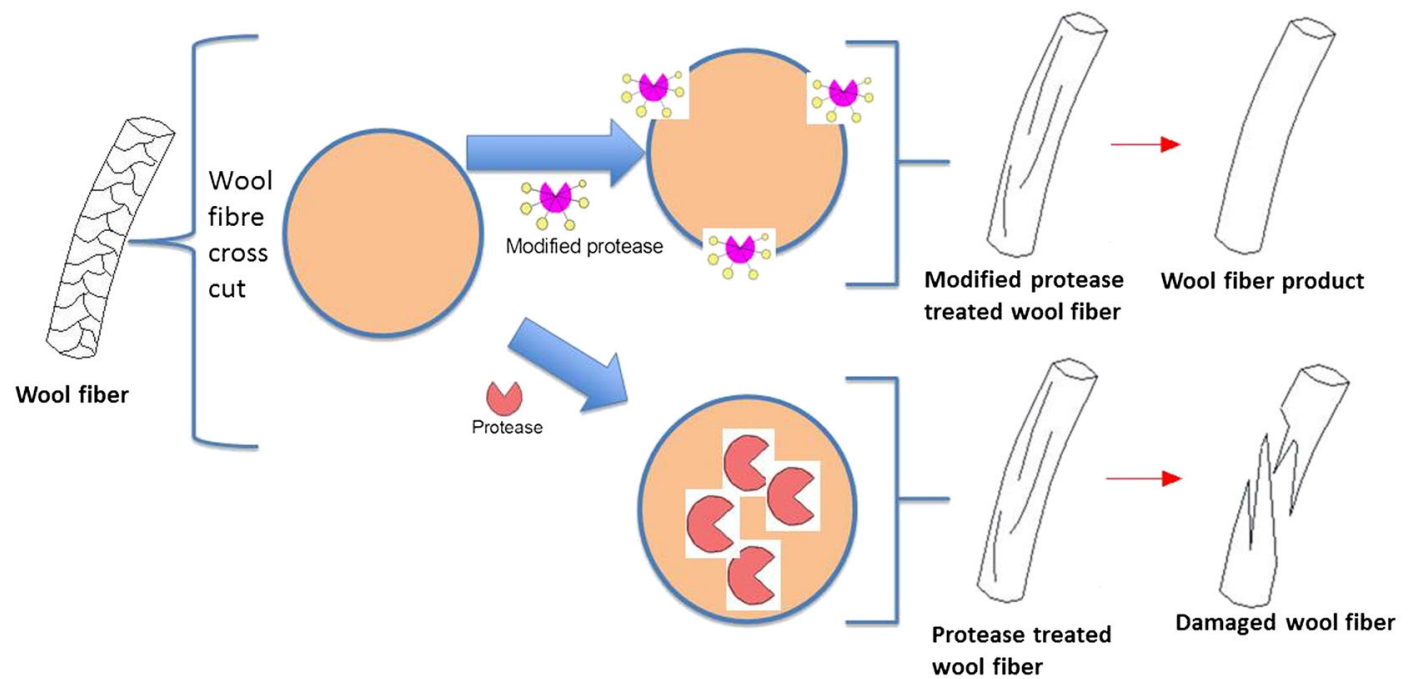

Fig. 5 Mechanism on anti-felting finishing of wool by proteases and modified proteases

Figs. 4 and 5, the best results are achieved with genetic or chemically modified proteases with larger molecular weight. Other approaches for anti-felting treatments include the combination of different enzymes, chemical and physical pretreatments. A detailed summary of the work done for antifelting treatments in the last 15 years is described in Table S3.

\section{Transglutaminases for wool modification}

Transglutaminases (EC2.3.1.13), also named proteinglutamine $\gamma$-glutamyl transferases, are a family of enzymes found in many microorganisms, plants, and animal tissues (Motoki and Seguro 1998; Yokoyama et al. 2004; Strop 2014, McDevitt \& Winklet WO 99/60,200). Transglutaminases catalyze the acyl transfer between the carboxyamide group of peptide-bound glutamine residues (acyl donors) and a variety of primary amines (acyl acceptors), including the amino group of lysine residues in certain proteins. In this case, proteins can cross-link via intra- or inter- $\varepsilon$ - $(\gamma$-glutamyl $)$ lysine isodipeptide bonds once the primary amine is the amino group of the peptide-bound lysine as shown in Fig. 6 (Motoki et al. 1998; Strop 2014), increasing the protein stability and resistance to chemicals and proteases (Mehta et al. 2002).

Transglutaminases can also be used in protein modification by the covalent bonding of the compounds containing primary amines (e.g. cadaverine). If the amine is bi-functional, the cross-linking of proteins can also occur via $N, N^{\prime}(\gamma$ glutamyl) polyamine bridges (Cortez et al. 2004). Currently, transglutaminases have been involved in many applications to attach proteins and peptides to small molecules, polymers, surfaces, DNA, and other proteins. The properties of wool fabrics modified by transglutaminases are summarized in Table S4. Transglutaminase treatment showed the ability to recover tensile strength after previous chemical or protease treatments (Cortez et al. 2005; Cardamone 2007; Du et al. 2007; Gaffar-Hossain et al. 2008; Ge et al. 2009; Zhang et al. 2010; Montazer et al. 2011, 2012). Other effects include 
Fig. 6 The reactions catalyzed by transglutaminase including a cross-linking reaction between glutamic acid $(G l u)$ and lysine (Lys) residues of proteins or peptides, $\mathbf{b}$ acyl transfer reaction, and c deamidation (Kieliszek and Misiewicz 2014)

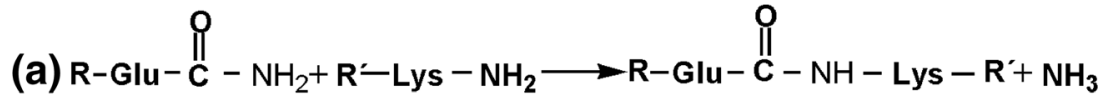<smiles></smiles><smiles>CP[Ga]C(=O)NN[R]#N</smiles>

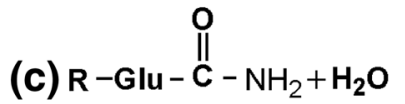<smiles>C=[Ru][Ge]C(=O)O[Hg]N</smiles>

the enhancement of the dyeing properties of wool fabrics (Cui et al. 2008). Grafting proteins into wool fibers by transglutaminase can also alter their physical/mechanical properties. Cortez et al. (2007) investigated transglutaminase-mediated grafting of silk proteins into wool and found that it could repair the fiber damage caused in earlier processing, with increased bursting strength and reduced levels of felting shrinkage.

\section{Coloration of wool using redox enzymes}

Laccase enzymes have been described as agents for hair coloration and can be also applied for dyeing of wool (Fu et al. 2012). It is known that many polymerized phenolic compounds can be obtained with laccases from hydroquinone, catechol, dopamine, guaiacol, and ferulic acid. Laccases belong to the class of multi-copper oxidoreductases that can catalyze the oxidation of various substrates such as mono-, di-, and polyphenols; substituted phenols (amino phenols, methoxyphenols, etc.); aromatic amines; lignin; mercaptan; and ascorbate (Ryan et al. 2003; Montazer et al. 2009). The substrate range of laccases can be expanded when a laccase/ mediator system (LMS) is used (Thurston 1994).

Hydroquinone and ferulic acid can be polymerized in present laccase or peroxidase and form pigment inside wool (Shin et al. 2001). The color depth of wool fabrics obtained can be tunned by the amount of hydroquinone previously added on the fabric. The mordant processing with chromium compounds helps the fixation of the colored hydroquinone derivatives into the wool fabrics.

Ryan et al. (2003) reported that wool dyeing process can be performed in a dye solution with a dyeing precursor $(2,5-$ diaminobenzenesulfonic acid) and dye modifiers (catechol and resorcinol) and laccase without any dyeing auxiliaries. Different depths of colors on the fabrics were obtained by changing the time of laccase treatment and concentration of the modifiers. The dyeing experiments with catechol and resorcinol show that the concentration was not statistically significant for the color depth to the catechol but was very significant to the resorcinol. To get a deep shade color, catechol should be used in high concentration while resorcinol should be used in low concentration. The fabrics dyed with catechol presented redder and bluer with increasing modifier concentration, whereas other fabrics dyed with resorcinol appeared yellower and greener. The position of the second $\mathrm{OH}$ group in the molecule of the modifier affects the coloration and the hue of samples. Laccase oxidizes the phenolic compounds, converting substrates (catechol and resorcinol) to reactive quinone species first, then the reactive quinine species react with amines forming 1,4-Michael-type adducts (shown in Table 1). The cross section of the enzymatically dyed wool was observed using a microscope, and it was found that such colorant can penetrate into the mass of wool fibers.

Munteanu et al. (2006) found that the cyclic voltammetry had a synergistic effect on wool dyeing when ultrasound was combined with enzymatic oxidation using laccase and a high color depth was obtained. Ultrasound enhanced the mass transport of the charged species near the working electrode, and a higher amount of ABTS ions was transported to the wool surface, resulting in deeper wool coloration.

Montazer et al. (2009) explored the effect of laccase on the physical properties of the wool fabric. It was found that the wool fabric pretreated with laccase had a higher water absorption and lower values of $a^{*}$ and $b^{*}$, thus decreasing the fabric lightness. It was also shown that the dyeing of laccasepretreated wool fabric with madder obtained a lower lightness because the laccase-treated wool adsorbed more water-soluble dye in the bath. It means that the laccase pre-treatment is valid for fabric coloration in the case of madder. The properties of wool fabric dyed with redox enzymes are shown in Table 1.

\section{Enzymatic processing of silk}

The conventional degumming of silk fibers is carried out with soap and alkali at $95^{\circ} \mathrm{C}$ and $\mathrm{pH} 9-10$, which can achieve the complete removal of sericin. However, the harsh condition such as high temperature and alkalinity will partially damage the silk fibroins and result in a decrease in fiber strength, which is considered as the main disadvantage of the conventional degumming of silk (Arami et al. 2007). As an alternative approach, enzymatic degumming of silk using proteases offers the advantages of minimum fiber damage, has less consumption of energy, and is environmentally benign. Table S5 summarizes the properties of silk fabrics after enzymatic and conventional degumming. 
Table 1 Coloration of wool with redox enzymes

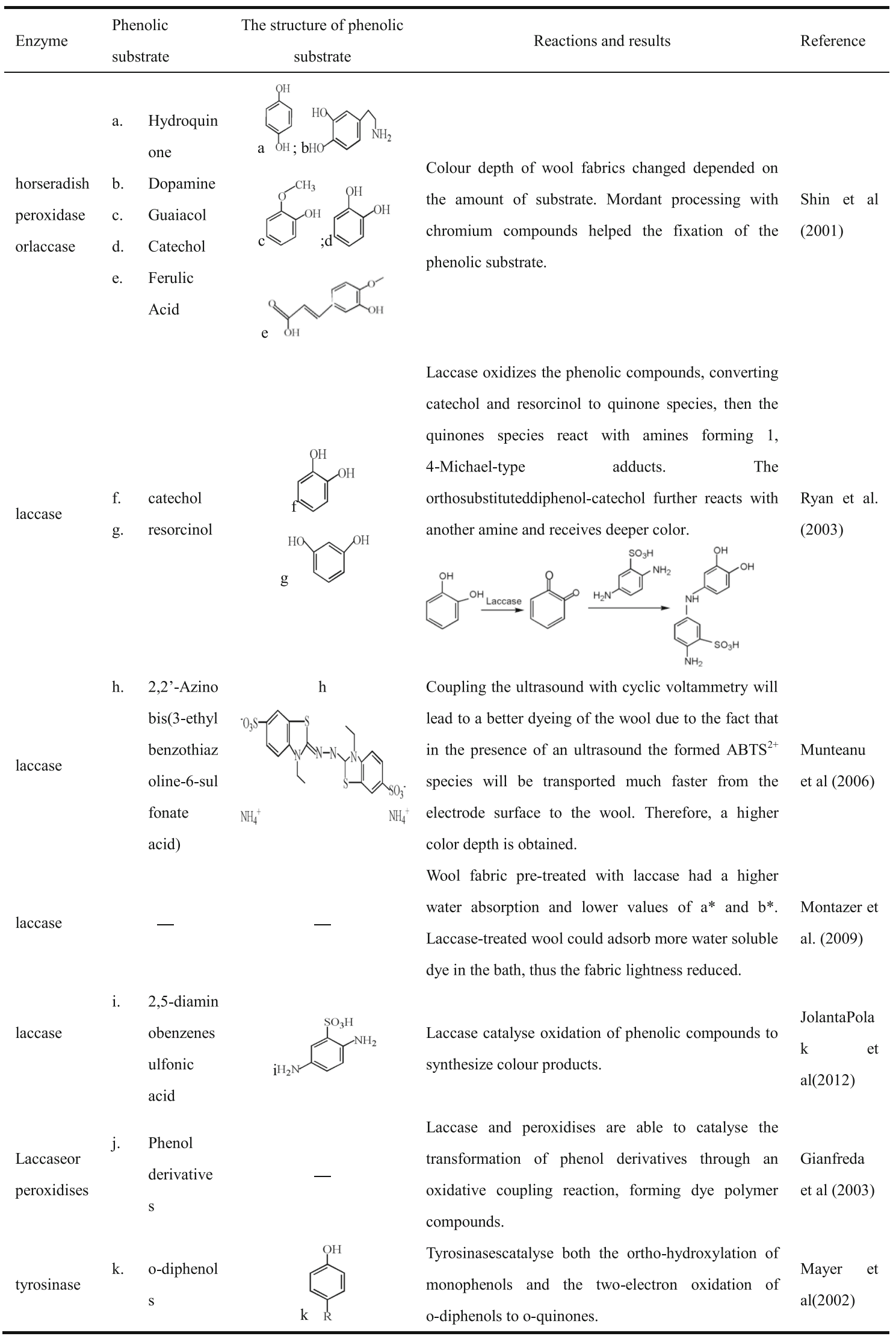


Fig. 7 Tyrosinase-initiated conjugation of GFP with chitosan (Chen et al. 2003)

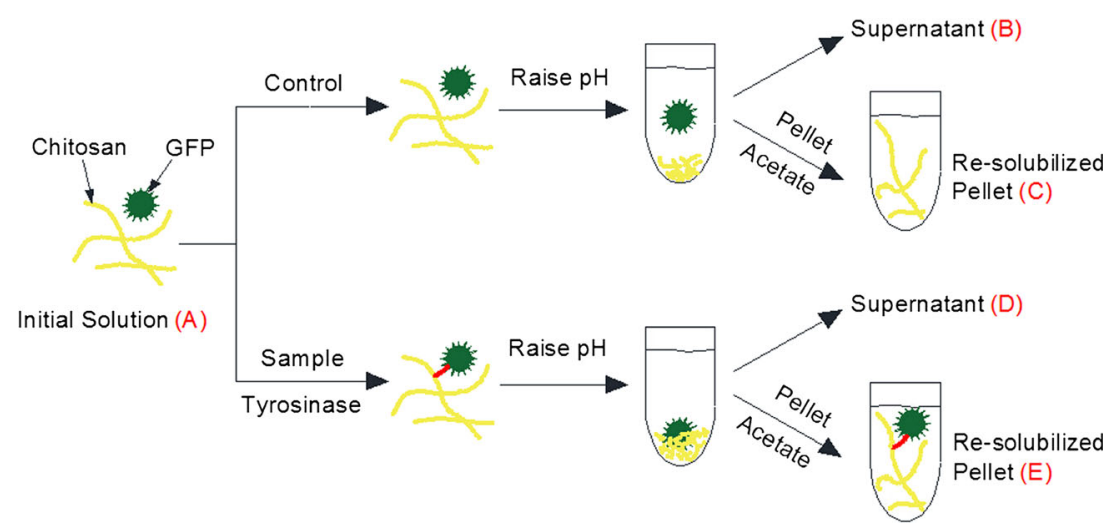

Freddi et al. (2003) investigated the effects of neutral proteases on the degumming of silk fabrics and reported that the degumming efficacy was highly dependent on the enzyme dosages and incubation time. As a consequence of complete sericin removal, the quality of the protease-treated silk in terms of handle and tensile properties could be noticeably increased due to the lower extent of chemical and physical stresses to which silk was subjected during enzymatic processing compared to the traditional chemical process. Other spot reports on silk degumming mention the combination of lipase and proteases (Gulrajani et al. 2000). Mahmoodi et al. (2010) mention the use of ultrasound to enhance the enzymatic degumming.

\section{Biofunctionalization of silk and fibroin-based products using tyrosinase}

Tyrosinases (EC 1.14.18.1) known as polyphenol oxidases are copper-containing enzymes widely distributed in all domains of life including animals, plants, and microorganisms (Xing et al. 2015). They are bi-functional enzymes that catalyze both the hydroxylation of monophenols to $o$-diphenols and the subsequent oxidation of the diphenols to $o$-quinones ( $\mathrm{Yi}$ et al. 2011). On the one hand, the quinones can spontaneously polymerize to form melanins or high molecular weight compounds. On the other hand, active quinones can also react with amines, amino acids, peptides, and proteins, affording not only new functional materials but also the functional modification of tyrosine-containing protein materials. For instance, several researchers investigated the feasibility of tyrosinase for the modification of proteins such as gelatine, casein, and sericin (Aberg et al. 2004; Anghileri et al. 2007; Chen et al. 2001, 2002;). A scheme for the tyrosinase linkage and isolation of soluble protein (like GFP) and chitosan is presented in Fig. 7 (Chen et al. 2003). The formation of $o$-quinones was the determining step of the grafting reaction (Chen et al. 2003; Sampaio et al. 2005). Tyrosinase can modify the tyrosine residues of fibroin proteins and introduce a wide variety of functional groups into silk fibers (Freddi et al. 2006) linking silk fibroin with chitosan. Table S6 shows the properties of biofunctionalization of silk using tyrosinase.

Kang et al. (2004a) also indicated that tyrosinase can oxidize the tyrosyl residues in silk fibroin with oxygen, resulting in the production of $o$-quinone residues which will react with amino groups to form the inter- or intramolecular crosslinks through the nonenzymatic process as shown in Fig. 8. Based on this evidence, they further revealed that the cross-linking between silk fibroin and chitosan occurred mainly through Michael addition reactions (Kang et al. 2004b). A main reaction between the amino groups in chitosan and $o$-quinone which was the oxidation product of the tyrosyl residue in silk fibroin was confirmed by UV spectroscopy (Gyung et al. 2004). The cross-linked SF/chitosan conjugate had a small particle size because of tight and strong bonding forces between the SF and chitosan molecular chains.

Tyrosinase-mediated cross-linking between silk fibroin and chitosan can be used not only in biomedical applications due to their unique properties and nontoxicity of conjugate but also in the functional modification of silk fibers. Wang et al. (2014) analyzed the impacts of the tyrosinase on the structure<smiles>O=C1C=CC(C[S-])=CC1=O</smiles>

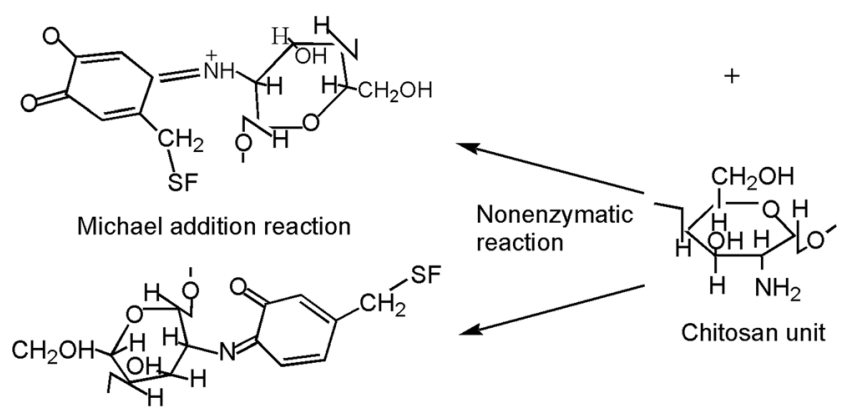

Maillard reaction (Schiff base)

Fig. 8 Silk fibroin/chitosan conjugate cross-linked by tyrosinase (Kang et al. 2004a; Kang et al. 2004b) 
Fig. 9 Tyrosinase-catalyzed grafting of chitosan on silk fibers (Taddei et al. 2013; Wang et al. 2014)<smiles>CN[C@H](Cc1ccc(O)cc1)C(C)=O</smiles>

Silk fibroin

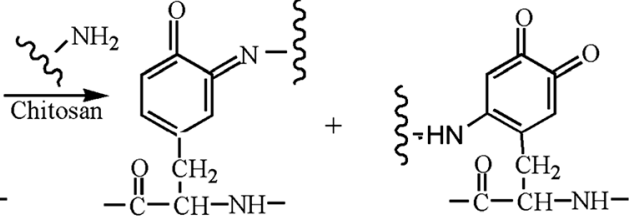

Silk-Chitosan conjugate of silk fibroin and the efficacy of the tyrosinase-catalyzed grafting of chitosan onto silk fibers. The result indicates that chitosan could be adsorbed on silk fibers via electrostatic interactions and other weak forces. Meanwhile, the amine groups of chitosan might react with the $o$-quinone residues oxidized from the tyrosyl residues of silk fibers. For the silk fabric treated with tyrosinase and chitosan, the strength and crease-resistant ability simultaneously improved owing to the covalent grafting of chitosan as well as the electrostatic forces between chitosan and silk fibroin. In addition, the efficacy of the graft reaction was also related with the accessibilities of tyrosinase and chitosan to the potential grafting sites in silk fibers.

The simultaneous coloration and functionalization (deodorizing ability, UV protection capacity, antioxidant activity, and hydrophilicity) of silk, wool, and nylon fabrics with the tyrosinase-catalyzed oxidation products of phenol (caffeic acid) were investigated, and the results showed that tyrosinase-catalyzed caffeic acid products can be used as potential colorants and functional finishes (Sun et al. 2013). In addition, the potential for using tyrosinase to graft the bovine lactoferrin onto Bombyx mori silk fibroin and gelatin was also examined based on the similar mechanism shown in Fig. 9 (Taddei et al. 2013; Wang et al. 2014). With regard to other polyphenol oxidase for silk modification, Guo et al. (2013) investigated the structure and properties of $\varepsilon$-polylysinegrafted silk fibers catalyzed by laccase. The wet wrinkle resistance of the modified silk fabrics was also noticeably improved.

Sericin has been discarded as a waste for many years, simultaneously causing environmental pollution in silk industry. Actually, the sericin from the degumming process can be applied in many fields such as cosmetics, biomaterials, and textiles (Zhang et al. 2004). Many works on the recycling and reutilization of sericin from degumming wastewater have been undertaken since the last century (Yamada and Nomura 1998; Capar et al. 2008; Vaithanomsat and Kitpreechavanich 2008).

Agaricus bisporus tyrosinase was proved to catalyze the oxidation of $57 \%$ tyrosine residues of silk sericin purified from industrial wastewater under homogeneous reaction conditions. Oxidized sericin peptides could undergo nonenzymatic coupling with chitosan under homogeneous reaction conditions, as demonstrated by infrared spectroscopy (Anghileri et al. 2007). Wu et al. (2008) obtained bioactive peptides from the sericin recovered from silk industry wastewater by using a protease. This study firstly established an effective biological method to produce sericin bioactive peptides, showing their potential as valuable ingredients in the food, cosmetic, and medicine industries.

\section{Conclusion and future outlook}

The potential of enzyme-based modification of proteinbased fibers is here reviewed. Proteases, in particular, have been applied in wool processing to impart shrink resistance and to silk degumming. Transglutaminases have a wide application in remediating damage of wool, antibacterial finishing, hydrophilic finishing, and color fixing in dyeing. Laccases show a great potential for wool and hair coloration. Tyrosinases can be valuable for silk modification and functionalization. All the abovementioned enzymatic processes offer great advantages over the traditional treatments due to their selectivity, specificity, and mild treatment conditions as well as nontoxic and environmentally friendly characters. The majority of these enzyme treatments were carried out on a lab scale. Future work needs to put emphasis on the know-how of enzymatic modification of protein-based fibers and focus on the tailoring of enzyme and processing routes for industrialization. New possibilities are open for application of biomodified silk and wool materials for cosmetic and pharma applications.

Acknowledgments This work was financially supported by the National Natural Science Foundation of China $(21274055,51373071$, 31201134 and 31470509), the Program for New Century Excellent Talents in University (NCET-12-0883), the Program for Changjiang Scholars and Innovative Research Team in University (IRT1135), the Jiangsu Provincial Natural Science Foundation of China (BK2012112), and the Fundamental Research Funds for the Central Universities (JUSRP51312B).

Conflict of interest The authors declare that they have no competing interests.

Ethical approval This article does not contain any studies with human participants performed by any of the authors. 


\section{References}

Aberg CM, Chen T, Olumide A, Raghavan SR, Payne GF (2004) Enzymatic grafting of peptides from casein hydrolysate to chitosan. Potential for Value-added Byproducts from Food Processing Wastes J Agric Food Chem J 52:788-793

Altman GH, Diaz F, Jakuba C, Calabro T, Horan RL, Chen J, Lu H, Richmond J, Kaplan DL (2003) Silk-based biomaterials. Biomaterials 24:401-416

Anghileri A, Lantto R, Kruus K, Arosio C, Freddi G (2007) Tyrosinasecatalyzed grafting of sericin peptides onto chitosan and production of protein-polysaccharide bioconjugates. J Biotechnol 127:508-519

Arami M, Rahimi S, Mivehie L, Mazaheri F, Mahmoodi NM (2007) Degumming of Persian silk with mixed proteolytic enzymes. J Appl Polym Sci 106:267-275

Arai T, Freddi G, Innocenti R, Kaplan DL, Tsukada M (2001) Acylation of silk and wool with acid anhydrides and preparation of waterrepellent fibers. J Appl Polym Sci 82:2832-2841

Araújo R, Sliva C, Machado R, Casal M, Cunha AM, Rodriguez-Cabello JC, Cavaco-paulo A (2009) Proteolytic enzyme engineering: a tool for wool. Biomacromolecules 10:1655-1661

Bishop DP, Shen J, Heine E, Hollfelder B (1998) The use of proteolytic enzymes to reduce wool-fibre stiffness and prickle. J Text I 89:546-553

Braaten AW (2005) Wool. In: Steele V (ed) Encyclopedia of clothing and fashion. Thomson Gale, London, pp. pp. 441-pp. 443

Capar G, Aygun SS, Gecit MR (2008) Treatment of silk production wastewaters by membrane processes for sericin recovery. J Membrane Sci 325:920-931

Cardamone JM (2007) Enzyme-mediated crosslinking of wool part I: transglutaminase. Textile Res J 77:214-221

Cavaco-Paulo A, Silva CJSM (2002) Treatment of animal hair fibres with modified proteases. European Patent. WO03097927

Chen T, Embree HD, Wu LQ, Payne GF (2002) In vitro protein-polysaccharide conjugation: tyrosinase-catalyzed conjugation of gelatin and chitosan. Biopolymers 64:292-302

Chen T, Vazquez-Duhalt R, Wu CF, Bentley WE, Payne GF (2001) Combinatorial screening for enzyme-mediated coupling. Tyrosinase-catalyzed coupling to create protein-chitosan conjugates. Biomacromolecules 2:456-462

Chen TH, Small DA, Wu LQ, Rubloff GW, Ghodssi R, Vazquez-Duhalt R, Bentley WE, Payne GF (2003) Nature-inspired creation of protein-polysaccharide conjugate and its subsequent assembly onto a patterned surface. Langmuir 19:9382-9386

Cortez J, Bonner PLR, Griffin M (2004) Application of transglutaminases in the modification of wool textiles. Enzyme Microb Tech 34:64-72

Cortez J, Bonner PLR, Griffin M (2005) Transglutaminase treatment of wool fabrics leads to resistance to detergent damage. J Biotechnol 116:379-386

Cortez J, Anghieri A, Bonner PLR, Griffin M, Freddi G (2007) Transglutaminase mediated grafting of silk proteins onto wool fabrics leading to improved physical and mechanical properties. Enzyme Microb Tech 40:1698-1704

Cui L, Du G, Chen J, Wang Q, Wang P, Fan X (2008) Effect of microbial transglutaminase on dyeing properties of natural dyes on wool fabric. Biocatal Biotransfor 26:399-404

Du GC, Cui L, Zhu Y, Chen J (2007) Improvement of shrink-resistance and tensile strength of wool fabric treated with a novel microbial transglutaminase from Streptomyces hygroscopicus. Enzym Microb Technol 40:1753-1757

Erlacher A, Sousa F, Schroeder M, Jus S, Kokol V, Cavaco-Paulo A, Guebitz GM (2006) A new cuticle scale hydrolysing protease from Beauveria brongniartii. Biotechnol Lett 28:703-710

Freddi G, Anghileri A, Sampaio S, Buchert J, Monti P, Taddei P (2006) Tyrosinase-catalyzed modification of Bombyx mori silk fibroin: grafting of chitosan under heterogeneous reaction conditions. J Biotechnol 125:281-294

Freddi G, Mossotti R, Innocenti R (2003) Degumming of silk fabric with several proteases. J Biotechnol 106:101-112

Fu JJ, Nyanhongo GS, Gubitz G, Cavaco-Paulo A, Kim S (2012) Enzymatic colouration with laccase and peroxidase: recent progress. Biocatal Biotransfor 30:125-140

Gaffar-Hossain KM, Juan AR, Tzanov T (2008) Simultaneous protease and transglutaminase treatment for shrink resistance of wool. Biocatal Biotransfor 26:405-411

Ge F, Cai Z, Zhang H, Zhang R (2009) Transglutaminase treatment for improving wool fabric properties. Fibre Polym 10:787-790

Gulrajani ML, Agarwal R, Grover A, Suri M (2000) Degumming of silk with lipase and protease. Indian J Fibre Text Res 25:69-74

Guo FY, Yang MY, Cao Y, Xing TL (2013) Preparation, structure and properties of $\varepsilon$-polylysine grafted silk fabric with laccase. Adv Mat Res 796:195-198

Gyung DK, Ki HL, Chang SK, Joong HN, Young HP (2004) Silk fibroin/ chitosan conjugate crosslinked by tyrosinase. Macromol Res 12: 534-539

Hakimi O, Knight DP, Vollrath F, Vadgama P (2007) Spider and mulberry silkworm silks as compatible biomaterials. Composites Part B 38: 324-337

Hu X, Kaplan D, Cebe P (2007) Effect of water on the thermal properties of silk fibroin. Thermochim Acta 461:137-144

Jin H, Bai X, Wang P, Zheng W, Xue HQ, Niu FL, Zhou XY (2013) Silk fiber-based microphotonic devices. Scientiarum Natura Universitatis Sunyatseni 52:6-10

Jus S, Schroeder M, Guebitz GM, Heine E, Kokol V (2007) The influence of enzymatic treatment on wool fibre properties using PEGmodified proteases. Enz. Microb Technol 40:1705-1711

Kang GD, Lee KH, Ki CS, Nahm JH, Park YH (2004a) Silk fibroin/ chitosan conjugate crosslinked by tyrosinase. Macromol Res 12: 534-539

Kang GD, Lee KH, Ki CS, Park YH (2004b) Crosslinking reaction of phenolic side chains in silk fibroin by tyrosinase. Fibers Polymers 5: 234-238

Kieliszek M, Misiewicz A (2014) Microbial transglutaminase and its application in the food industry. A review. Microbiol 59:241-250

Lantto R, Schönberg C, Buchert J, Heine E (2004) Effects of laccasemediator combinations on wool. Textile Res J 74:713-717

Mahmoodi NM, Arami M, Mazaheri F, Rahimi S (2010) Degradation of sericin (degumming) of Persian silk by ultrasound and enzymes as a cleaner and environmentally friendly process. J Clean Prod 18:146151

McDevitt JP, Winkler J (2000) Method for enzymatic treatment of wool. U.S. WO 1999060200

Mehta K, Rao RU, Chandrashekar R (2002) Transglutaminase of the lower organisms. Across the link between life and death. Minerva Biotecnologica 14:129-134

Middlebrook WR, Phillips H (1941) The application of enzymes to the production of shrinkage-resistant wool and mixture fabrics. J Soc Dye Colour 57:137-143

Montazer M, Dadashian F, Hemmatinejad N, Farhoudi K (2009) Treatment of wool with laccase and dyeing with madder. Appl Biochem Biotech 158:685-693

Montazer M, Lessan F, Pajootan E, Dadashian F (2011) Treatment of bleached wool with trans-glutaminases to enhance tensile strength, whiteness, and alkali resistance. Appl Biochem Biotech 165:748759

Montazer M, Pajootan E, Lessan F (2012) Microbial trans-glutaminase enhances the physical and mechanical properties of depigmented wool. Eng Life Sci 12:216-222

Motoki M, Seguro K (1998) Transglutaminase and its use for food processing. Trends Food Sci Tech 9:204-210 
Munteanu FD, Basto C, Gubitz G, Cavaco-Paulo A (2006) Staining of wool using the reaction products of ABTS oxidation by laccase: synergetic effects of ultrasound and cyclic voltammetry. Ultrason Sonochem 14:363-367

Rippon JA (1992) The structure of wool. Society of dyers and colorists, Bradford, pp. 31-51

Ryan S, Schnitzhofer W, Tzanov T, Cavaco-Paulo A, Gübitz G (2003) An acid-stable laccase from Sclerotium rolfsii with potential for wool dye decolourization. Enzyme Microb Tech 33:766-774

Sampaio S, Taddei P, Monti P, Buchert J, Freddi G (2005) Enzymatic grafting of chitosan onto Bombyx mori silk fibroin: kinetic and IR vibrational studies. J Biotechnol 116:21-33

Schroeder M, Lenting HBM, Kandelbauer A, Silva CJSM, Cavaco-Paulo A, Gübitz G (2006) Restricting detergent protease action to surface of protein fibres by chemical modification. Appl Microbiol Biot 72: 738-744

Shen J, Rushforth M, Cavaco-Paulo A, Gübitz G, Lenting H (2007) Development and industrialisation of enzymatic shrink-resist process based on modified proteases for wool machine washability. Enzyme Microb Tech 40:1656-1661

Shin H, Gubitz G, Cavaco-Paulo A (2001) "In situ” enzymatically prepared polymers for wool coloration. Macromol Mater Eng 286:691694

Silva CJSM, Gübitz G, Cavaco-Paulo A (2006a) Optimisation of a serine protease coupling to Eudragit S-100 by experimental design techniques. J Chem Technol Biotechnol 81:8-16

Silva CJSM, Prabaharan M, Gübitz G, Cavaco-Paulo A (2005) Treatment of wool fibres with subtilisin and subtilisin-PEG. Enzyme Microb Tech 36:917-922

Silva CJSM, Zhang Q, Shen J, Cavaco-Paulo A (2006b) Immobilization of proteases with a water soluble-insoluble reversible polymer for the treatment of wool. Enzyme Microb Tech 39:634-640

Simpson WS (2002) Chemical processes for enhanced appearance and performance. In: Simpson WS, Crawshaw GH (eds) Wool: science and technology. Woodhead Publishing Limited, Cambridge, pp. pp. 215-pp. 236

Sionkowska A, Planecka A (2011) The influence of UV radiation on silk fibroin. Polym Degrad Stab 96:523-528

Smith E, Schroeder M, Guebitz G, Shen JS (2010) Covalent bonding of protease to different sized enteric polymers and their potential use in wool processing. Enzyme Microb Tech 47:105-111

Smith E, Zhang Q, Shen J, Schroeder M, Silva CJSM (2008) Modification of Esperase by covalent bonding to Eudragit polymers L100 and S100 for wool fibre surface treatment. Biocatal Biotransfor 26:391-398

Strop P (2014) Versatility of microbial transglutaminase. Bioconjug Chem 25:855-862

Sun SS, Xing TL, Tang RC (2013) Simultaneous coloration and functionalization of wool, silk, and nylon with the tyrosinase- catalyzed oxidation products of caffeic acid. Ind Eng Chem Res 52:8953-8961

Taddei P, Chiono V, Anghileri A, Vozzi G, Freddi G, Ciardelli G (2013) Silk fibroin/gelatin blend films crosslinked with enzymes for biomedical applications. Macromol Biosci 13:1492-1510

Thurston CF (1994) The structure and function of fungal laccases. Microbiology 140:19-26

Vaithanomsat P, Kitpreechavanich V (2008) Sericin separation from silk degumming wastewater. Sep Purif Technol 59:129-133

Vepari C, Kaplan DL (2007) Silk as a biomaterial. Progin Polym Sci 32: 991-1007

Wang P, Wang Q, Fan XR, Yuan JG, Cui L (2010) A review of feltproofing of wool with proteases. Dyeing Finishing 36:46-49

Wang P, Yu ML, Cui L, Yuan JG, Wang Q, Fan XR (2014) Modification of Bombyx mori silk fabrics by tyrosinase-catalyzed grafting of chitosan. Eng Life Sci 14:211-217

Wu JH, Wang Z, Xu SY (2007) Preparation and characterization of sericin powder extracted from silk industry wastewater. Food Chem 103:1255-1262

Wu JH, Wang Z, Xu SY (2008) Enzymatic production of bioactive peptides from sericin recovered from silk industry wastewater. Process Biochem 43:480-487

Xing R, Zheng AP, Wang F, Wang L, Yu YP, Jiang AH (2015) Functionality study of Na6PMo11 FeO40 as a mushroom tyrosinase inhibitor. Food Chem 175:292-297

Yamada H, Nomura M (1998) Fibrous article for contact with skin. Japan Patent 10-001872A

Yang Y, Li S (1993) Silk fabric non-formaldehyde crease-resistant finishing using citric acid. J Text I 84:638-644

Yi W, Dubois C, Yahiaoui S, Haudecoeur R, Belle C, Song H, Hardré R, Réglier M, Boumendjel A (2011) Refinement of arylthiosemicarbazone pharmacophore in inhibition of mushroom tyrosinase. Eur J Med Chem 46:4330-4335

Yokoyama K, Nio N, Kikuchi Y (2004) Properties and applications of microbial transglutaminase. Appl Microbiol Biot 64:447-454

Zhang R, Cai Z, Zhang H (2010) Studies on the remedial effect of transglutaminase on protease anti-felting treated wool. J Text I 101:1015-1021

Zhang YQ, Tao ML, Shen WD, Zhou YZ, Ding Y, Ma Y, Zhou WL (2004) Immobilization of Lasparaginase on the microparticles of the natural silk sericin protein and its characters. Biomaterials 25: 3751-3759

Zhou W, Ji HJ, Wang Q, Wang P, Fan XR, Cai C (2011) Promoting effect of keratinase in wool anti-felting finishing with protease. $\mathrm{J}$ Textile Res 32:82-88

Zou H, Zhang S (2007) Pretreatment technique of cool wool/ramie complex yarn. Journal of Wuhan University of Science and Engineering 20:24-28 